\title{
N-rich Electron Acceptor: Triplet Harvesting in Multichromophoric Pyridoquinoxaline and Pyridopyrazine-based Organic Emitters
}

\author{
Bahadur Sk, ${ }^{a}$ Samarth Sharma, ${ }^{a}$ Anto James,,${ }^{a, b}$ Subhankar Kundu, ${ }^{a}$ and Abhijit Patra ${ }^{* a}$ \\ aDepartment of Chemistry, Indian Institution of Science Education and Research Bhopal, Madhya Pradesh, 462066, India \\ ${ }^{b}$ Department of Chemistry, Indian Institution of Science Education and Research Thiruvananthapuram, Kerala, 695551, India \\ *abhijit@iiserb.ac.in
}

\begin{abstract}
Control of nonradiative deactivation of triplet states and tuning the singlet-triplet energy gap $\left(\Delta \mathrm{E}_{\mathrm{ST}}\right)$ are the major challenges to develop materials exhibiting thermally activated delayed fluorescence (TADF) and room temperature phosphorescence (RTP). Herein, we propose a new class of multichromophoric tridonoracceptor $\left(D_{3}-A\right)$ compounds with rigid and flexible m-spacer having $\mathrm{N}$ rich pyridoquinoxaline $(P Q)$ and pyridopyrazine $(P Z)$ acceptor core, respectively. The molecule with carbazole $(\mathrm{Cz})$ donors at meta to quinoxaline $(Q X)$ nitrogen of rigid $P Q$ core exhibits TADF. Whereas, the variation of the linkage position of $C z$ to $P Q$ as well as twisted and flexible PZ core show predominantly RTP due to relatively higher singlet-triplet energy gap $\left(\Delta \mathrm{E}_{\mathrm{ST}}\right)$. Increasing the donor strength with phenoxazine (PO) in PZ system leads to simultaneous TADF and RTP. Further, we demonstrate the promising scope of all-organic triplet harvesting materials in solid-state security encryption.
\end{abstract}

Smart organic donor-acceptor (D-A) based multichromophores have gained profound interest in recent years owing to the efficient harvesting of the triplet excited states. ${ }^{[1]}$ The triplet state could be emissive by thermally activated delayed fluorescence (TADF) or the radiative decay at ambient conditions, commonly known as room temperature phosphorescence (RTP). ${ }^{[2]}$ Such emitters are making their way in a wide variety of photonics applications like organic light-emitting diodes (OLEDs), $\left.{ }^{[1 \mathrm{~b},} 3\right]$ sensors, ${ }^{[4]}$ security devices, ${ }^{[5]}$ time-resolved luminescence imaging ${ }^{[6]}$ etc. The key challenges are to control the dynamic collisional quenching of triplet excited state and lowering the energy gap between the excited singlet $\left(\mathrm{S}_{1}\right)$ and triplet $\left(\mathrm{T}_{1}\right)$ states $\left(\Delta \mathrm{E}_{\mathrm{ST}}\right) .{ }^{[5 a,}{ }^{7]}$ The lower $\Delta \mathrm{E}_{\mathrm{ST}}$ value promotes the photon upconversion from excited triplet states to the emissive singlet states through reverse intersystem crossing (RISC) leading to TADF. ${ }^{[1 b]}$ The excited state intramolecular charge transfer (ICT) in donor-acceptor (D-A) molecules with spatially-separated the highest occupied molecular orbitals (HOMOs) and the lowest unoccupied molecular orbitals (LUMOs) is conducive to low $\Delta \mathrm{E}_{\mathrm{ST}}$ values. The CT interactions also favour a strong spin-orbit coupling (SOC) through the mixing of isostructural singlet and triplet electronic excited states. ${ }^{[8]}$ Consequently, a high rate of intersystem crossing (ISC) along with stable triplet excited states leads to persistent or ultralong RTP in certain D-A compounds. ${ }^{[5 a}$, 7b]

The CT interactions depend not only on the molecular geometry but also vary with the relative orientation of $D$ and $A$ units. ${ }^{[19,9]}$ ICT significantly differs among positional isomers with different substitution positions of donors on the acceptor core. ${ }^{[10]}$ Chen et al. demonstrated the switching between TADF and RTP in phenothiazine-benzophenone based D-A compounds invoking the concept of twisted intramolecular charge transfer (TICT) and planarized intramolecular charge transfer (PICT). ${ }^{[19]}$ The TICTbased probe was shown to exhibit TADF. RTP was observed in a more rigid conformer exhibiting PICT. Bryce and coworkers observed RTP in phenothiazine-dibenzothiophene-S,S-dioxide based D-A-D pair by introducing steric hindrance on the donor units. ${ }^{[2 c]}$ The flexibility and the rigidity of the molecular backbone in the $D_{2}$-A pair significantly influence the charge transfer that may tune the TADF and RTP. Xie et al. reported delayed emission with high quantum efficiency in the red region $\left(\lambda_{e m}=600 \mathrm{~nm}\right)$ with rigid planar dibenzo[a,c]phenazine as the acceptor core and 9,9dimethylacridan as donor units. ${ }^{[11]}$ Interestingly, the emission wavelength was tuned from green to red by increasing the number of donor units from $D-A, D_{2}-A$, to $D_{3}-A$ architecture by controlling the ICT effect. Amidst several recent reports, a molecular design strategy unraveling the abstruse role of the central acceptor core along with conformational analysis in multichromophoric organic emitters for tunable and efficient TADF and RTP is still intriguing albeit challenging.

Herein, we have examined the role of $\mathrm{N}$-rich acceptor units along with $\pi$-spacers in terms of flexibility/ rigidity and twisted/ planar geometry on emission properties of $D_{3}-A$ molecules at different timescale. The central core of pyridoquinoxaline $(P Q)$ or pyridopyrazine (PZ) serves as facile acceptor units owing to the multiple nitrogen centers, which induces strong SOC, and thus enhance the ISC (Figure 1). ${ }^{[2 \mathrm{~d}]}$ Furthermore, the adjacent phenyl spacers also offer a distinctive synthetic advantage in regulating the molecular flexibility/ rigidity of the central core. The molecule with carbazole $(\mathrm{Cz})$ donors at meta to quinoxaline $(\mathrm{QX})$ nitrogen of rigid PQ core showed enhanced TADF due to the low $\triangle \mathrm{E}_{\mathrm{ST}}$. However, the higher $\Delta \mathrm{E}_{S T}$ due to variation of the linkage position of $\mathrm{Cz}$ (para to $\mathrm{QX}$ nitrogen) to $\mathrm{PQ}$ and $\mathrm{PZ}$ core resulted in predominant RTP. The simultaneous TADF and RTP were achieved employing $\mathrm{PO}$ as donors in PZ system. Tuning TADF and RTP through a rational design strategy of new $D_{3}-A$ architecture, as demonstrated in the present communication, would contribute to develop advanced optoelectronic materials for security encryption and identification.
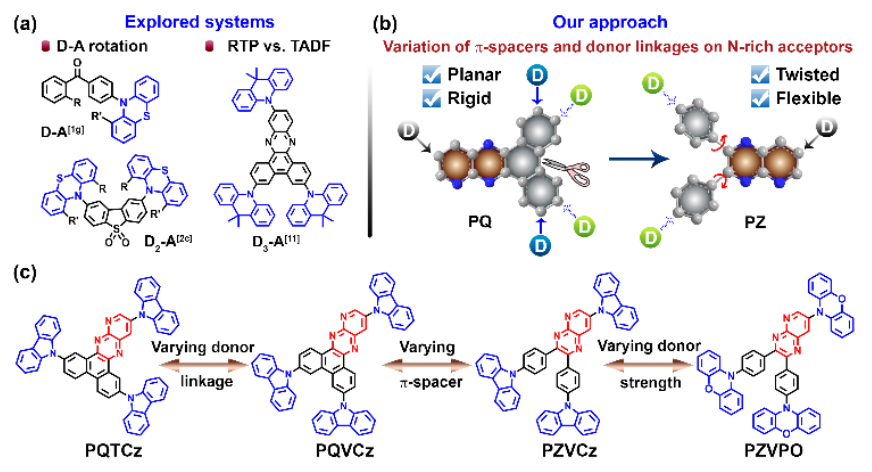

Figure 1. Design strategy of triplet harvesting materials: representative electron donor (D) and acceptor (A) based charge transfer compounds with D-A, D-A-D and $D_{3}-A$ architecture. (b) Schematic illustration of our approach representing planar dibenzopyridoquinoxaline (T-shaped: PQT and V-shaped: PQV) and twisted diphenylpyridopyrazine (PZV) acceptor units, and (c) the molecular structures of tridonor-acceptor $\left(\mathrm{D}_{3}-\mathrm{A}\right)$ compounds with carbazole $(\mathrm{Cz})$ and phenoxazine (PO) as donor units: PQTCz, PQVCz, PZVCz and PZVPO; D-A linkage, $\Pi$-spacer and donor strength are varied. 
Quinoxaline is a well-known electron acceptor unit due to the presence of two electronegative $\mathrm{sp}^{2}$ hybridized nitrogen atoms. ${ }^{[12]}$ Phenazine also possesses similar electron-deficient characteristics as quinoxaline. ${ }^{[13]}$ The presence of another nitrogen-containing heterocycle to the quinoxaline unit leads to the $P Q$ motif, with better electron accepting capability than quinoxaline or phenazine. Similarly, PZ is more electron deficient than pyrazine. The suitable disposition of $\pi$-spacers (phenyl groups) leads to the development of dibenzopyridoquinoxaline and diphenylpyridopyrazine. The phenyl $\pi$-spacers do not alter the electron-withdrawing capabilities of $\mathrm{PQ}$ or $\mathrm{PZ}$, rather allow synthetic flexibility and a range of viable options to introduce the donor substituents. Henceforth, dibenzopyridoquinoxaline and diphenylpyridopyrazine are abbreviated as $P Q$ and $P Z$, respectively. The significant difference between $P Q$ and $P Z$ core lies in the molecular flexibility/ rigidity induced by the linkage pattern of phenyl spacers (Figure 1b). Donor substitutions at 2,7 and 3,6- positions of $P Q$ lead to $T$ and V-shaped molecular geometry. ${ }^{[10]}$ We introduce multiple electron donor units covalently linked with central $P Q$ and $P Z$ core for the development of a new series of multichromophoric $D_{3}-A$ molecules. Considering the efficient electron-donating properties, high thermal stability and low-cost, $\mathrm{Cz}$ and $\mathrm{PO}$ were chosen as the donor units. ${ }^{[14]}$ Palladium-catalyzed Buchwald-Hartwig crosscoupling reactions (C-N coupling) of tribromo-PQT, PQV, and $\mathrm{PZV}$ with $\mathrm{Cz}$ and $\mathrm{PO}$ resulted in $\mathrm{PQTC}, \mathrm{PQVC}, \mathrm{PZVCz}$, and PZVPO (Figure 1c). All the compounds were characterized by NMR spectroscopic and mass spectrometric analysis.
The $D_{3}-A$ compounds absorb predominantly in the UV-region along with a prominent broad absorption band in the visible region. The lower-energy absorption bands are attributed to the extended $\pi$-conjugation between the donor and the acceptor units. ${ }^{[10,15]}$ Whereas, the higher energy absorption bands are ascribed to $\pi$ $\pi^{*}$ transitions. Strong fluorescence with broad emission bands were observed for PQTCz, PQVCz, and PZVCz in toluene $(5 \mu \mathrm{M})$ at room temperature $(\mathrm{RT}$, Figure $2 \mathrm{a}-\mathrm{C})$. A relatively weak emission was noticeable for PZVPO in toluene at RT (Figure 2d, strong DA pair, dark TICT, vide infra). ${ }^{[10,15 a]}$ On increasing the solvent polarity from toluene to dichloromethane, a gradual bathochromic shift in the emission maxima was observed for all compounds. The emission maxima were found to be independent of the excitation wavelengths. The spectral broadening of the emission bands with increasing solvent polarity and positive solvatochromic behaviour are the two characteristic features indicative of strong ICT in the $D_{3}-A$ compounds. ${ }^{[10,15 a, 16]}$ Notably, the Stokes shift in PQTCz (m-substitution) is higher than PQVCz and PZVCz ( $p$ substitution) in all solvents, which is in agreement with the more facile ICT in the former. ${ }^{[10]}$ The largest Stokes shift $(150 \mathrm{~nm}, 5245$ $\mathrm{cm}^{-1}$ ) exhibited by PZVPO among the $\mathrm{D}_{3}-\mathrm{A}$ compounds suggests the efficient $C T$ interactions due to stronger donor characteristics of $\mathrm{PO}$ over $\mathrm{Cz}$. The Lippert-Mataga plots further substantiate the ICT behaviour.

The fluorescence decays of all the compounds were measured in the solvents with varying polarity. A biexponential fluorescence decay for all the compounds at RT is possibly due to the emission from the locally excited (LE) and the charge transfer state. ${ }^{[15 a, 17]}$ To get the decay associated emission spectra for a particular
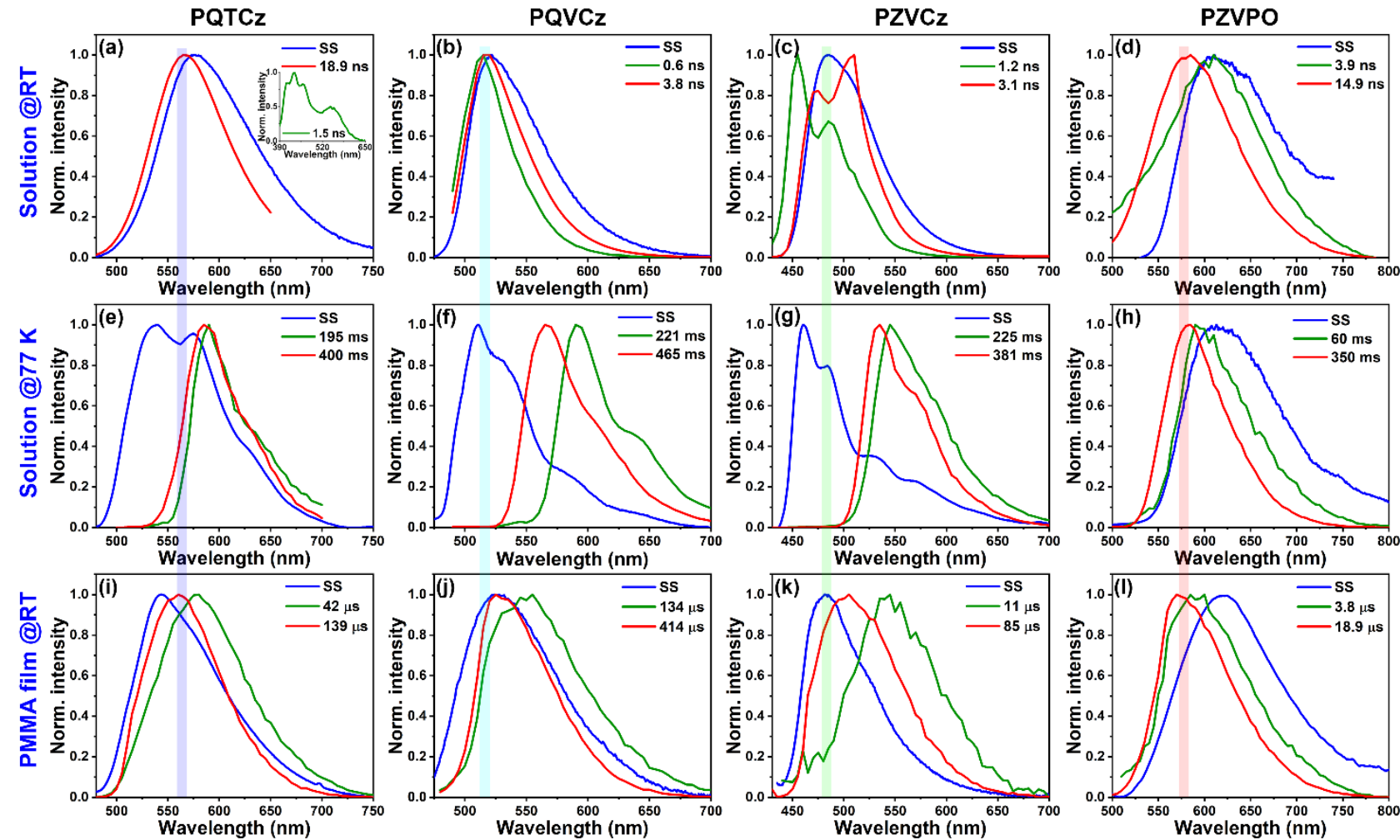

Figure 2 Time-resolved emission spectra (TRES) from nanosecond to millisecond timescale: normalized emission spectra of $D_{3}-A$ compounds in toluene at room temperature (a-d), in toluene at $77 \mathrm{~K}(\mathrm{e}-\mathrm{h})$ and in polymethyl methacrylate (PMMA) films at room temperature (RT: $\left.22-25^{\circ} \mathrm{C}, \mathrm{i}-\mathrm{I}\right)$, respectively for $(\mathrm{a}, \mathrm{e}, \mathrm{i}) \mathrm{PQTCz}(\mathrm{a}$ Inset: spectrum at $1.5 \mathrm{~ns}$ depicting LE emission), (b, f, j) PQVCz, (c, g, k) PZVCz and (d, h, I) PZVPO. Spectra were recorded using $\lambda$ ex $=465 \mathrm{~nm}$ [steady state (SS), $450 \mathrm{~W}$ Xe lamp], $\lambda_{\mathrm{ex}}=468 \mathrm{~nm}$ [picosecond (ps) diode laser] and $461 \mathrm{~nm}$ [millisecond (ms) spectraLED] for PQTCz, PQVCz and PZVPO, respectively and $\lambda_{\mathrm{ex}}$ $=420 \mathrm{~nm}$ (SS, $450 \mathrm{~W}$ Xe lamp), $\lambda_{\mathrm{ex}}=410 \mathrm{~nm}$ (ps diode laser) and $417 \mathrm{~nm}$ (ms spectraLED) for PZVCz. The solid bars indicate the similarity of emission peak position of $\mathrm{D}_{3}-\mathrm{A}$ compounds at different timescale in solution at $\mathrm{RT}, 77 \mathrm{~K}$, and in polymer film. 
timescale, the emission decays at 350 to $750 \mathrm{~nm}$ with the interval of $5 \mathrm{~nm}$ were measured. The reconstructed time-resolved emission spectra (TRES) of PQTCz at $1.5 \mathrm{~ns}$ and $18.9 \mathrm{~ns}$ show two distinct spectral profiles (Figure 2a). The emission spectrum obtained at $1.5 \mathrm{~ns}$ is similar to that of $\mathrm{Cz}$ emission in toluene (Figure 2a). It refers to the LE emission. ${ }^{[17]}$ The emission at 18.9 ns resembles the steady-state (SS) emission and is attributed to the charge transfer (CT) fluorescence (Figure 2a). Similarly, the TRES of PQVCz, PZVCz, and PZVPO in toluene at ambient conditions are shown in Figure $2 b-d$.

The phosphorescence spectra and associated decays of $D_{3}-A$ compounds were recorded at an ultralow temperature in liquid nitrogen $(77 \mathrm{~K})$ using $450 \mathrm{~W}$ Xe lamp [steady-state (ss)], picosecond (ps) diode laser and millisecond (ms) spectraLED as the excitation source. The ss emission spectra of $D_{3}-A$ compounds at $77 \mathrm{~K}$ showed emission bands with multiple humps (Figure 2e-h) and were significantly different compared to those obtained at RT (Figure 2a-d). The biexponential emission decays at $77 \mathrm{~K}$ at fast timescale were similar to that observed at RT due to the fluorescence from LE and CT states (Figure 2a-d). However the decay measurements at slower timescale at $77 \mathrm{~K}$ revealed ultralong phosphorescence ranging from few milliseconds to 0.5 seconds (Figure 2e-h).

The phosphorescence emission maxima of PQTCz were observed at 585 and $590 \mathrm{~nm}$ with decay time 400 and $195 \mathrm{~ms}$, respectively (Figure $2 e$ ). PQVCz emits with peaks at 565 and 590 $\mathrm{nm}$ with decay time 465 and $221 \mathrm{~ms}$, respectively (Figure 2f). The phosphorescence emission peak maxima of $\mathrm{PZVCz}$ were noticeable at 535 and $545 \mathrm{~nm}$ with decay time 381 and $225 \mathrm{~ms}$, respectively (Figure $2 \mathrm{~g}$ ). The phosphorescence decay time of PZVPO is 60 and $350 \mathrm{~ms}$ with a peak centered at $585 \mathrm{~nm}$ and $595 \mathrm{~nm}$, respectively (Figure $2 \mathrm{~g}$ ), which are very close to the fluorescence bands observed in toluene at RT (585 and $610 \mathrm{~nm}$, Figure 2d). The multiexponential phosphorescence decays suggest more than one triplet charge-transfer state $\left({ }^{3} \mathrm{CT}\right)$ due to the presence of multiple donor units. The lower $\Delta \mathrm{E}_{\mathrm{ST}}$ values $(<0.5$ $\mathrm{eV}$ ) of $\mathrm{D}_{3}-\mathrm{A}$ compounds based on experimental data indicate the possible thermally activated RISC. The long-lived emission decay at RT with the oxygen-free condition of $D_{3}-A$ compounds in toluene revealed the prominent delayed emission characteristics of PQTCz. However, no longer component emission was observed for PQVCz, PZVCz, and PZVPO under the same condition.

Further, the $D_{3}-A$ compounds were doped in polymethyl methacrylate (PMMA) matrix to ascertain the triplet harvesting characteristics in the rigid media. All the compounds emit (ss) in the distinct regions of the visible spectrum (Figure $2 \mathrm{i}-\mathrm{I}$ ), ranging from cyan $(P Z V C z)$ to green (PQTCz and $P Q V C z)$ to red (PZVPO). The decays at the ns timescale monitored at the emission maxima indicate multiple emitting species at RT. It could be due to the emission from the singlet ( $L E, I C T)$, triplet $\left(T_{1}\right)$ states and aggregates. ${ }^{[2 d, 5 a, 7 c, 18]}$ PQTCz film at RT exhibits emission peaks at 565 and $580 \mathrm{~nm}$, with the decay time 139 and $42 \mu \mathrm{s}$, respectively (Figure 2i). The emission maximum at $565 \mathrm{~nm}$ obtained at $\mu$ s timescale matches with TRES at RT in toluene (18.9 ns), indicating TADF in polymer film (Figure 2a and 2i). Whereas, it shows phosphorescence peak at $590 \mathrm{~nm}$ at $77 \mathrm{~K}$ in toluene (Figure 2e). The TRES measured using sensitive gated intensified charge-coupled device (iCCD) camera further ascertain the TADF of PQTCz film (Figure 3a). Unlike the toluene
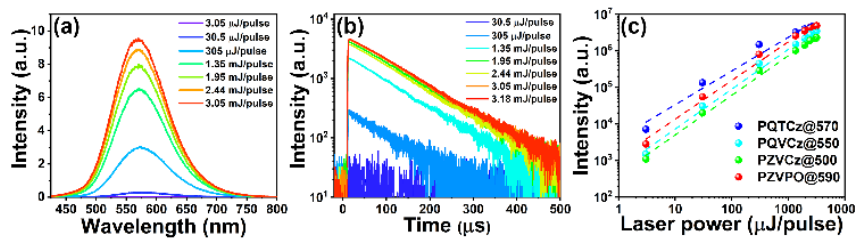

Figure 3 (a) Time-resolved emission spectra (TRES) with varying laser power (pulse width $=5-7 \mathrm{~ns}$ ) of PMMA films of PQTCz at ambient conditions. Spectra were recorded using intensified charge-coupled device (iCCD) camera ( $\lambda_{\mathrm{ex}}=$ $355 \mathrm{~nm})$. (b) The emission decay kinetics $\left(\lambda_{\mathrm{ex}}=355 \mathrm{~nm}, \lambda_{\mathrm{em}}=570 \mathrm{~nm}\right)$ of PQTCz-PMMA film with varying laser power at ambient conditions. (c) The linear fitting of the emission intensity of PMMA films of $D_{3}-A$ compounds as a function of excitation power $\left(\lambda_{\mathrm{ex}}=355 \mathrm{~nm}\right)$; the linear dependence of emission characteristic with laser power suggests unimolecular decay process.

solution at RT, PQVCz film displays distinct longer component emission at 525 and $550 \mathrm{~nm}$ at decay time 414 and $135 \mu \mathrm{s}$, respectively (Figure $2 \mathrm{j}$ ). It also shows phosphorescence $(77 \mathrm{~K})$ with peak maxima at 565 and $590 \mathrm{~nm}$ (Figure 2f).

D-A compounds with flexible acceptor cores are likely to exhibit delayed fluorescence. ${ }^{[19]}$ We anticipated the same for $D_{3}-A$ compounds with flexible $\mathrm{PZ}$ core. The peaks at 510 and $545 \mathrm{~nm}$ with a respective decay time of 85 and $11 \mu \mathrm{s}$ of PZVCz film (Figure 2k) resemble with phosphorescence peaks at $77 \mathrm{~K}$ (Figure 2g). Thus, PZVCz in PMMA film exhibits RTP. Similarly, PZVPO film shows long-lived decays with peaks at 570 and $590 \mathrm{~nm}$ having decay time 18.9 and $3.8 \mu \mathrm{s}$, respectively (Figure 2l). The origin of long-lived decay in PZVPO film at ambient conditions is presumably due to mixed RTP and delayed fluorescence (vide infra). Further, the laser power-dependent emission spectra using iCCD camera and decay were recorded to elucidate the long-lived components of $D_{3}-A$ compounds in a rigid polymer matrix (Figure $3 a, b)$. A linear correlation of emission intensity with laser power for all the compounds signifies the unimolecular decay processes (Figure 3c), ruling out the triplet-triplet annihilation, as expected in TADF or RTP.

TD-DFT calculations, coupled with crystal structure investigations, shed light on the intriguing photophysics of $D_{3}-A$ compounds (Figure 4a-c). The computed energy levels of the lowest singlet $\left(E_{S_{1}}=2.12 \mathrm{eV}\right)$ and triplet $\left(E_{T_{1}}=1.99 \mathrm{eV}\right)$ excited states of PQTCz are very close to the values obtained from the experimental data (Figure $4 \mathrm{a})$. The lower $\Delta \mathrm{E}_{\mathrm{ST}}(0.13 \mathrm{eV})$ due to strong CT facilitated by the decoupled HOMO-LUMO levels enables the photon upconversion through RISC (Figure 4a). Thus, a prominent TADF was observed in the PQTCz film. Additionally, the similar nature of transition configurations and isosurfaces of $S_{1}$ and other triplet excited states $\left(T_{1}\right.$ and $\left.T_{2}\right)$ increase the probability of SOC, leading to high triplet yield. ${ }^{[2,, 8 a, 20]}$ Whereas, a higher $\Delta \mathrm{E}_{\mathrm{ST}}(0.29 \mathrm{eV})$ and a greater number of energy transition channels $\left(S_{1}\right.$ to $T_{1}, T_{2}$, and $T_{3}$ ) were observed for $P Q V C z$ leading to phosphorescence at ambient conditions (Figure 4a). On the other hand, PZVCz exhibits higher $\triangle \mathrm{E}_{\mathrm{ST}}(0.26 \mathrm{eV})$ and multiple ISC channels between $S_{1}$ and $T_{n}$ (Figure 4a), and phosphorescence was observed from PZVCz film. The molecular structure of PZVPO obtained from crystal structure analysis revealed a highly twisted geometry (Figure $4 b$ ). The dihedral angles between the central PZ core and the phenyl linker groups are $144.77^{\circ}$ and $118.79^{\circ}$, while the dihedral angle between the $\pi$ spacers and phenoxazine donor unit is close to $80^{\circ}$. The donor (PO) units are connected directly to the acceptor core exhibiting a dihedral angle of $127.35^{\circ}$. Furthermore, a pair of $\mathrm{CH}^{\cdots} \pi(2.86$ $\AA)$ and $\mathrm{CH} \cdots \mathrm{HC}(2.31 \AA)$ intermolecular interactions between $\pi$ - 
(a)

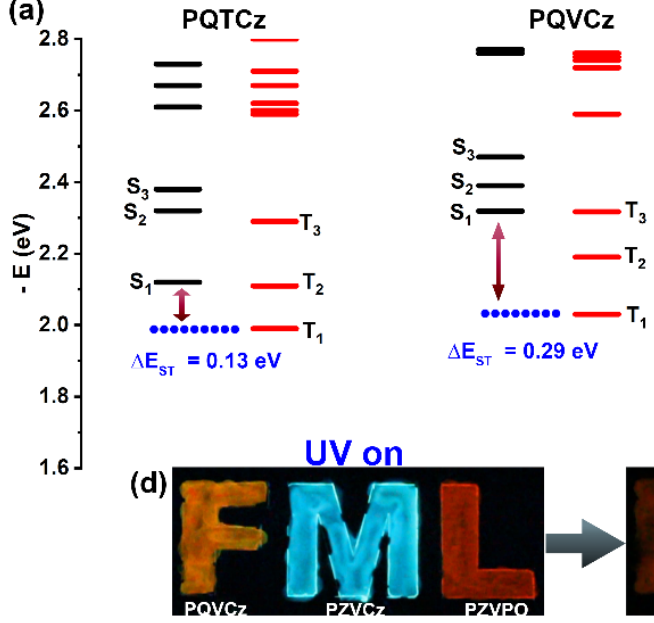

PZVCz

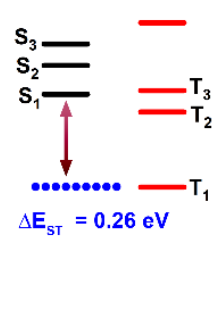

PZVPO

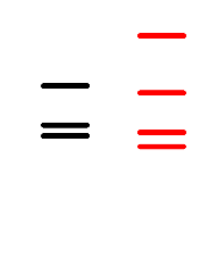

$\Delta \mathrm{E}_{\mathrm{ST}}=0.02 \mathrm{eV}$

(b)

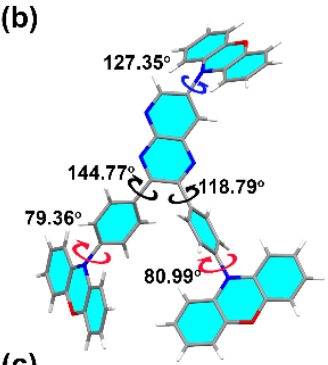

(c)

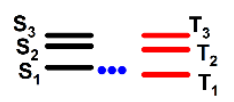

(e)
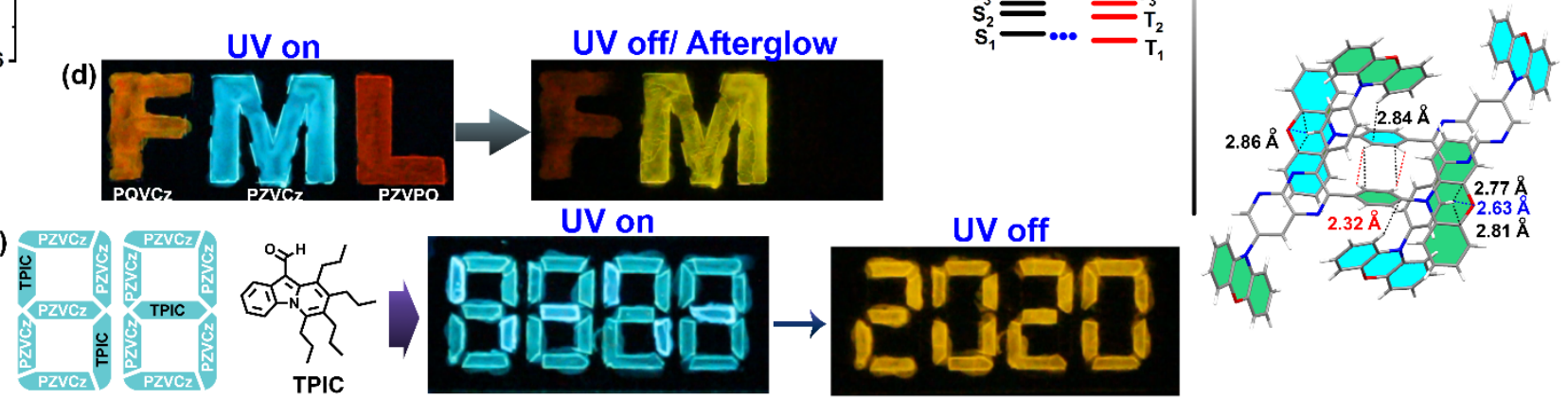

Figure 4 (a) Time dependent-density functional theory (TD-DFT) computed [B3LYP/6-311G(d,p)] energy levels and possible intersystem crossing (ISC) channels of PQTCz, PQVCz, PZVCz and PZVPO at the singlet $\left(\mathrm{S}_{n}\right)$ and triplet $\left(\mathrm{T}_{n}\right)$ states; the values of $\mathrm{S}_{1}-\mathrm{T}_{1}$ energy gaps $\left(\triangle \mathrm{E}_{\mathrm{ST}}\right)$ are indicated. (b) The molecular structure of PZVPO obtained from the single crystal X-ray diffraction analysis and significant dihedral angles are shown depicting twisted nature of the molecule. (c) The intra- and intermolecular interactions in a single crystal of PZVPO; the strong intermolecular $\mathrm{C}-\mathrm{H}$-..O interactions (2.63-2.86 $\AA$ ) between the phenoxazine oxygen and $\mathrm{CH}$ of $\pi$-spacer phenyl group is indicated. The dimer of PZVPO is further stabilized by the intermolecular interactions between the $\pi$-spacer phenyl groups $[\mathrm{CH} \cdots \mathrm{HC}, 2.32 \AA$; grey $(\mathrm{C})$, blue $(\mathrm{N})$, red $(\mathrm{O})$. (d) The digital images of PQVCz, PZVCz, and PZVPO-doped PMMA films at RT under the excitation of UV-lamp $\left(\lambda_{\mathrm{ex}}=365 \mathrm{~nm}\right)$, and the photographs after instant turning off the UV irradiation. (e) Demonstration of timescale encoding for security application of PZVCzembedded PMMA film in combination with a cyan emitting 6,7,8,9-tetrapropylpyrido[1,2-a]indole-10-carbaldehyde (TPIC, $\tau \sim 10 \mathrm{~ns}$ ) fluorophore. On excitation ( $\lambda$ ex $=365 \mathrm{~nm}$ ), the patterned security feature is unrecognizable due to the strong cyan fluorescence from TPIC and PZVCz. The encrypted feature of '2020' constructed with phosphorescent PZVCz can be identified easily by the naked eye after the excitation is switched off; photographs were captured using Canon EOS camera with 18-55 mm lens.

spacer aromatic phenyl groups generate a dimer like twisted structure along a axis (Figure 4c). These strong intermolecular interactions in the crystals of PZVPO could reduce energy loss through nonradiative relaxation channels. ${ }^{[5 c, 21]}$ Additionally, a very low $\Delta \mathrm{E}_{\mathrm{ST}}$ value $(0.02 \mathrm{eV})$ owing to the strong $\mathrm{CT}$ interactions coupled with long-lived triplet state contributed to the delayed fluorescence and radiative triplet emission in the rigid matrix at ambient conditions (Figure 4a).

Tunable fluorescence and RTP with the afterglow feature of $D_{3-}$ A compounds in polymer films were demonstrated through the encryption of FML (Figure 4d, written using PQVCz: F, PZVCz: M, and PZVPO: L). Greenish-yellow, cyan, and red fluorescence to greenish-orange, yellowish-green, and very weak red RTP, were observed, respectively, from PQVCz, PZVCz, PZVPO embedded PMMA films (Figure 4d). Further, we developed a facile information encryption pattern employing PZVCz thin film under ambient conditions (Figure 4e). The color-changing events were recorded using an image capturing Canon EOS camera. The film upon UV irradiation $\left(\lambda_{\mathrm{ex}}=365 \mathrm{~nm}\right)$ showed intense cyan fluorescence. A distinctly contrasting greenish-yellow phosphorescence was observed by naked eye after turning off the UV light source (Figure 4e). Thus, the encrypted information is visible multiple times through switching on/off the UV light.

In summary, we developed a new class of multichromophoric tridonor-acceptor compounds with rigid and flexible $\pi$ spacers based on pyridoquinoxaline and pyridopyrazine acceptor core, respectively. A strategy for tuning the TADF and RTP emission by controlling the charge transfer interactions through the variation of molecular geometry, as well as the relative orientation of donor and acceptor units, was demonstrated. The lower $\Delta \mathrm{E}_{\mathrm{ST}}$ value upon the $m$-substitution of donors on rigid pyridoquinoxaline core facilitates RISC leading to delayed fluorescence. Whereas, the relatively higher $\Delta \mathrm{E}_{\mathrm{ST}}$ values and close packing induced by the $p$-substitution of donors on both pyridoquinoxaline and flexible pyridopyrazine acceptor core, led to predominantly RTP. The potential afterglow feature of $D_{3}-A$ compounds was shown for security data encryption and identification. The present study elucidating the subtle role of D-A linkages coupled with the rigidity and flexibility of the new $\mathrm{N}$-rich central acceptor core lays a promising foundation for further development of all-organic materials for triplet harvesting.

\section{Acknowledgements}

The infrastructural support from IISERB, financial support from BRNS, DAE (No. 37(2)/14/06/2016BRNS/37020), and Council of Scientific and Industrial Research (CSIR), New Delhi, (No. $01(2878) / 17 / E M R-I I)$ is gratefully acknowledged. BSk and SK thank IISERB and UGC for fellowship. We thank Ms. Ashima Negi and Dr. A. Gupta at IISERB for helping to record decays using iCCD camera, and Dr. J. A. Mondal at BARC for fruitful discussion.

Keywords: Charge transfer - donor-acceptor systems room temperature phosphorescence - thermally-activated delayed fluorescence - pyridoquinoxaline 


\section{References:}

[1] (a) M. Lor, J. Thielemans, L. Viaene, M. Cotlet, J. Hofkens, T. Weil, C. Hampel, K. Mullen, J. W. Verhoeven, M. Van der Auweraer, F. C. De Schryver, J. Am. Chem. Soc. 2002, 124, 9918-9925; (b) H. Uoyama, K. Goushi, K. Shizu, H. Nomura, C. Adachi, Nature 2012, 492, 234; (c) K. Kawasumi, T. Wu, T. Y. Zhu, H. S. Chae, T. Van Voorhis, M. A. Baldo, T. M. Swager, J. Am. Chem. Soc. 2015, 137, 11908-11911; (d) S. Feuillastre, M. Pauton, L. H. Gao, A. Desmarchelier, A. J. Riives, D. Prim, D. Tondelier, B. Geffroy, G. Muller, G. Clavier, G. Pieters, J. Am. Chem. Soc. 2016, 138, 3990-3993; (e) D. M. E. Freeman, A. J. Musser, J. M. Fros, H. L. Stern, A. K. Forster, K. J. Fallon, A. G. Rapidis, F. Cacialli, I. McCulloch, T. M. Clarke, R. H. Friend, H. Bronstein, J. Am. Chem. Soc. 2017, 139, 11073-11080; (f) P. K. Samanta, D. Kim, V. Coropceanu, J. L. Bredas, J. Am. Chem. Soc. 2017, 139, 4042-4051; (g) C. J. Chen, R. J. Huang, A. S. Batsanov, P. Pander, Y. T. Hsu, Z. G. Chi, F. B. Dias, M. R. Bryce, Angew. Chem. Int. Ed. 2018, 57, 16407-16411; (h) S. Kundu, B. Sk, P. Pallavi, A. Giri, A. Patra, Chem. Eur. J. 2019, DOI:10.1002/chem.201904626.

[2] (a) J. M. Lupton, A. Pogantsch, T. Piok, E. J. W. List, S. Patil, U. Scherf, Phys. Rev. Lett. 2002, 89, 4; (b) H. Tanaka, K. Shizu, H. Nakanotani, C. Adachi, Chem. Mater. 2013, 25, 3766-3771; (c) J. S. Ward, R. S. Nobuyasu, A. S. Batsanov, P. Data, A. P. Monkman, F. B. Dias, M. R. Bryce, Chem. Commun. 2016, 52, 2612-2615; (d) M. Louis, H. Thomas, M. Gmelch, A. Haft, F. Fries, S. Reineke, Adv. Mater. 2019, 31, 1807887; (e) L. Zhan, C. Yang, Z. Chen, S. Gong, Y. Xiang, F. Ni, X. Zeng, G. Xie, Angew. Chem. Int. Ed. 2019, 58, 17651-17655; (f) J. Yuan, R. Chen, X. Tang, Y. Tao, S. Xu, L. Jin, C. Chen, X. Zhou, C. Zheng, W. Huang, Chem. Sci. 2019, 10, 5031-5038.

[3] F. B. Dias, K. N. Bourdakos, V. Jankus, K. C. Moss, K. T. Kamtekar, V. Bhalla, J. Santos, M. R. Bryce, A. P. Monkman, Adv. Mater. 2013, 25, 3707 3714.

[4] H. Liu, Y. Gao, J. Cao, T. Li, Y. Wen, Y. Ge, L. Zhang, G. Pan, T. Zhou, B. Yang, Mater. Chem. Front. 2018, 2, 1853-1858.

[5] (a) Z. An, C. Zheng, Y. Tao, R. Chen, H. Shi, T. Chen, Z. Wang, H. Li, R. Deng, X. Liu, W. Huang, Nat. Mater. 2015, 14, 685; (b) M. Gmelch, H. Thomas, F. Fries, S. Reineke, Sci. Adv. 2019, 5, eaau7310; (c) H. Shi, L. Song, H. Ma, C. Sun, K. Huang, A. Lv, W. Ye, H. Wang, S. Cai, W. Yao, Y. Zhang, R. Zheng, Z. An, W. Huang, J. Phys. Chem. Lett. 2019, 10, 595600 .

[6] (a) X. Xiong, F. Song, J. Wang, Y. Zhang, Y. Xue, L. Sun, N. Jiang, P. Gao, L. Tian, X. Peng, J. Am. Chem. Soc. 2014, 136, 9590-9597; (b) Z. He, H. Gao, S. Zhang, S. Zheng, Y. Wang, Z. Zhao, D. Ding, B. Yang, Y. Zhang, W. Z. Yuan, Adv. Mater. 2019, 31, 1807222.

[7] (a) M. A. El - Sayed, J. Chem. Phys. 1963, 38, 2834-2838; (b) H. Ma, Q. Peng, Z. An, W. Huang, Z. Shuai, J. Am. Chem. Soc. 2019, 141, 1010 1015; (c) H. Noda, X. Chen, H. Nakanotani, T. Hosokai, M. Miyajima, N. Notsuka, Y. Kashima, J. Brédas, C. Adachi, Nat. Mater. 2019, 18, 10841090.

[8] (a) L. Huang, L. Liu, X. Li, H. Hu, M. Chen, Q. Yang, Z. Ma, X. Jia, Angew. Chem. Int. Ed., 2019, 58, 16445-16450; (b) I. Bhattacharjee, N. Acharya, H. Bhatia, D. Ray, J. Phys. Chem. Lett. 2018, 9, 2733-2738.

[9] (a) C. S. Oh, D. S. Pereira, S. H. Han, H. J. Park, H. F. Higginbotham, A. P. Monkman, J. Y. Lee, ACS Appl. Mater. Interfaces 2018, 10, 35420 35429; (b) J. Lin, S. Li, Z. Liu, D. Chen, C. Huang, Y. Wei, Y. Chen, Z. Tsai, C. Lo, W. Hung, K. Wong, P. Chou, Chem. Mater. 2019, 31, 5981-5992; (c) J. Liu, T. Hu, Z. Li, X. Wei, X. Hu, H. Gao, G. Liu, Y. Yi, Y. YamadaTakamura, C. S. Lee, P. Wang, Y. Wang, J. Phys. Chem. Lett. 2019, 18881893.

[10] B. Sk, S. Khodia, A. Patra, Chem. Commun. 2018, 54, 1786-1789.

[11] F. Xie, H. Li, G. Dai, Y. Li, T. Cheng, M. Xie, J. Tang, X. Zhao, ACS Appl. Mater. Interfaces 2019, 11, 26144-26151.

[12] (a) G. Gokce, B. Karabay, A. Cihaner, M. Icli Ozkut, J. Polym. Sci. Part A: Polym. Chem. 2017, 55, 3483-3493; (b) H. Jiang, Y. Wu, A. Islam, M. Wu, W. Zhang, C. Shen, H. Zhang, E. Li, H. Tian, W. Zhu, ACS Appl. Mater. Interfaces 2018, 10, 13635-13644; (c) R. Pashazadeh, P. Pander, A. Bucinskas, P. J. Skabara, F. B. Dias, J. V. Grazulevicius, Chem. Commun. 2018, 54, 13857-13860.

[13] (a) Z. Zhang, Y. Wu, K. Tang, C. Chen, J. Ho, J. Su, H. Tian, P. Chou, J. Am. Chem. Soc. 2015, 137, 8509-8520; (b) P. Data, P. Pander, M. Okazaki,
Y. Takeda, S. Minakata, A. P. Monkman, Angew. Chem. Int. Ed. 2016, 55, 5739-5744.

[14] Y. Im, M. Kim, Y. J. Cho, J. Seo, K. S. Yook, J. Y. Lee, Chem. Mater. 2017, 29, 1946-1963.

[15] (a) J. R. Lakowicz, Principles of fluorescence spectroscopy, Springer, New York, 2006; (b) B. Dereka, A. Rosspeintner, R. Stezycki, C. Ruckebusch, D. T. Gryko, E. Vauthey, J. Phys. Chem. Lett. 2017, 8, 6029-6034.

[16] (a) S. Singha, D. Kim, B. Roy, S. Sambasivan, H. Moon, A. S. Rao, J. Y. Kim, T. Joo, J. W. Park, Y. M. Rhee, T. Wang, K. H. Kim, Y. H. Shin, J. Jung, K. H. Ahn, Chem. Sci. 2015, 6, 4335-4342; (b) M. Collot, S. Bou, T. K. Fam, L. Richert, Y. Mely, L. Danglot, A. S. Klymchenko, Anal. Chem. 2019, 91, 1928-1935.

[17] T. Suhina, S. Amirjalayer, B. Mennucci, S. Woutersen, M. Hilbers, D. Bonn, A. M. Brouwer, J. Phys. Chem. Lett. 2016, 7, 4285-4290.

[18] Y. Wang, J. Yang, Y. Tian, M. Fang, Q. Liao, L. Wang, W. Hu, B. Z. Tang, Z. Li, Chem. Sci. 2020, 11, 833-838.

[19] N. A. Kukhta, R. Huang, A. S. Batsanov, M. R. Bryce, F. B. Dias, J. Phys. Chem. C 2019, 123, 26536-26546.

[20] (a) J. Ye, L. Wang, H. Wang, H. Xie, Y. Qiu, Org. Electron. 2019, 70, 193204; (b) Z. He, H. Gao, S. Zhang, S. Zheng, Y. Wang, Z. Zhao, D. Ding, B. Yang, Y. Zhang, W. Z. Yuan, Adv. Mater., 2019, 31, 1807222.

[21] (a) A. Forni, E. Lucenti, C. Botta, E. Cariati, J. Mater. Chem. C 2018, 6, 4603-4626; (b) J. Yang, X. Zhen, B. Wang, X. Gao, Z. Ren, J. Wang, Y. Xie, J. Li, Q. Peng, K. Pu, Z. Li, Nat. Commun. 2018, 9, 840. 